\title{
The role of educational and professional bodies in guidance towards capacity planning
}

\author{
Peter Juliff \\ Professor and Head of School of Management \\ Information Systems \\ Deakin University \\ Burwood VIC 3125, Australia \\ Tele + 613 92446266; Fax + 61392446928 \\ E-mail:pjuliff@deakin.edu.au
}

\begin{abstract}
This paper examines the rationale for an Information Technology (IT) education policy for developing countries and suggests contributions which IT professional bodies may make towards its development. Areas covered include raising of the level of public awareness of IT, the need for a technical infrastructure and commercial expertise, the development of academic curriculum development and accreditation, the formulation of professional standards of practice, and the creation of joint training schemes with industry.
\end{abstract}

\section{Keywords}

Curriculum policies, professional development, accreditation, industry training

\section{INTRODUCTION}

The aim of this paper is to examine the respective roles of educational institutions and professional societies in the process of IT capacity building. It will address the levels at which IT education may be delivered and some rationales for each of those levels will be presented. In particular, it will emphasize the need for teacher education as a foundation for all other levels. 
The paper will suggest activities which might be undertaken by computing professional bodies to provide constructive assistance to this process. Some of the activities are able to be pursued in their own right and others will be in collaboration with the providers of IT education.

\section{The need for informed public opinion}

Information Technology has an ever increasing impact on society. It is a significant determinant of business practice, manufacturing efficiency, levels of employment, available public services and global communication. It may be regarded with enthusiasm or with suspicion but, in either case, public opinion should be well informed lest a Luddite mentality develop due to ill-founded fear and resentment. Computing technology has moved into the realm of consumables. The general community need not understand the principles of the computer's internal operation any more than they need to understand the principles on which the telephone or electricity work but, as with these other technologies, there is a need for a general appreciation of the capacity for its application in everyday life.

The news media often present a view of the technology which is emotionally biased either for or against a particular issue such as employment or privacy. It is virtually impossible for the general public to form an independent opinion on such matters when the technology concerned seems to be beyond their comprehension. The situation can only be remedied by education.

\section{The need for technical infrastructure}

As with all technologies, an educated and skilled workforce is required for the installation and maintenance of IT, if not for its manufacture. A manufacturing capacity provides independence as well as employment but may be difficult to justify in a developing country due to the high cost of initiation and the rapidity of changes in the technology. Developing countries' primary concern in planning educational policy should be the establishment of facilities to educate and train engineers and technicians to support installed technology in the workplace.

\section{The need for commercial expertise}

It is trite to say that technology has no purpose of itself and that its value lies in how it can be used to assist human endeavours. Despite this, much of the IT education currently found at all levels would seem to ignore this principle. IT is an enabling technology helping many commercial - using this term in its broadest sense - organizations work more effectively. For many other organizations it is an essential factor in their continued existence.

The driving force behind the majority of IT education initiatives in any developing country, arguably in any country at all, is the training of a workforce capable of using technology to foster the country's progress. Information Technology supports business and manufacturing efficiency and largely determines the level of services available to the general public. It provides a step rather than a curve in the level of production of goods and services in the same way as the steam engine aided manufacturing and mechanization aided agriculture. 


\section{ACADEMIC CURRICULUM DEVELOPMENT AND ACCREDITATION}

Education for a career in IT or education in IT for a career? The question provides a useful focus for considering the general issue of IT education. While it is obvious that every student won't want to study for a career in IT, it is becoming increasingly true that all careers - especially professional careers - will demand competence in IT. The last thirty years' history of IT systems in developed countries has failed to produce a specific IT manager career classification in any significant numbers. The management of the Information Technology resource continues to be the responsibility of the general business management.

Despite the emergence of information as arguably the most important asset possessed by any organization, its management is still largely left in the hands of end-users. The implication of this on the education programs offered to business managers in general is that a significant 'major' study in IT is a desirable component of all other professional education.

The levels of education needed encompass primary/secondary education, postsecondary and vocational education, tertiary education and postgraduate education.

\section{Primary/secondary education}

IT education at the primary and secondary levels should encourage familiarity with technology and dispel fear and mistrust. Technology should be neutral to gender, culture and school subject. The use of the technology should be encouraged in as many educational areas as possible and certainly not only in mathematics and science. Technology should be seen as an enabler, helping in tasks such as the retrieval of information and developing the basic skills of reading, writing and arithmetic. Given the preponderance of English language software products, the development of native language-based software is likely to be a desirable priority in many countries. China, for example, despite a language which is not friendly to screen and keyboard operations, has made significant progress in this area.

\section{Postsecondary and vocational education}

Contrasted with tertiary courses, those offered at postsecondary level are normally shorter in their duration and more limited in their scope. Despite these limitations, such courses train a paraprofessional level of IT employees able to develop systems from standard application software and to liaise between user groups and professional computing staff in an organization. The courses also offer a means whereby all staff whose daily work involves considerable interaction with computer-based systems may obtain a level of knowledge sufficient to understand the implications of dealing with the technology. The courses may lead to a certificate or diploma, or may be shorter and offered with no academic credit for attendance.

\section{Tertiary education}

Two key areas are required in tertiary education to support the growth of an IT infrastructure in a developing country and to contribute to the use of IT in the 
growth of commerce, industry and services. A cadre of engineering and technical support personnel must be trained to develop a local capacity for producing professional and technical staff who can install and maintain the hardware and communications resources needed to allow the widespread use of the technology.

A cadre of business information systems personnel must be trained who can integrate business, management and IT skills essential to business, manufacturing, government and service provision. The emphasis in the development of tertiary computing courses must move away from viewing technology as an end in itself and must concentrate on its use in adding value to commercial processes.

\section{Postgraduate education}

In addition to courses at an undergraduate level, IT studies need to be offered at a graduate diploma level to train graduates already in the workforce who want to upgrade their knowledge and skill in order to make an informed contribution to IT systems being developed within their organizations.

\section{PROFESSIONAL DEVELOPMENT RESPONSIBILITIES}

\section{The need for teacher education}

One of the prime requirements the widespread use of IT in education is the supply of educators who are qualified in IT. Expertise is needed at all levels of education. Policy makers responsible for teacher training and employment must be committed to provide funds, time release and recognition of achievement for those taking part in IT training. IT needs to be seen as a specialist area in education, along with the traditional specialties such as languages, science, mathematics and other school subjects. Too often IT has been seen as something which mathematics teachers do in their spare time. Such a limited view of IT use perpetuates the myth that IT is only for the mathematically-inclined and restricts the application of IT to technical areas.

It is significant that much of the ongoing contribution to IT education in the workplace is being undertaken primarily by professional bodies outside of the IT communities. National engineering, accounting and law societies have established educational programs and publications for members whose interests have become focused on IT. In addition, most countries have one or more IT professional societies whose main aim is the advancement of knowledge of their members. In Australia, and I suspect in other countries, the growth of membership in computing societies has been less than the growth of IT specialist areas in other professional bodies.

\section{The educational role of IT professional bodies}

Computing professional societies may make a number of specific contributions to their communities. For example, most IT professional societies engage in significant programs of ongoing education for their members. Much of this is done on a noncredit basis but the Australian Computer Society's (ACS) Certification Program, a formal course of study comprising two general and two specialist units administered by Deakin University and providing advanced standing in that university's MBA program, might be worth replicating in other countries. 


\section{The raising of IT awareness in the general community.}

In the early days of IT development and its permeation through the general community in Australia, the ACS conducted public programs such as 'Computer Week' or a similar title. The activities provided information to the general public about IT, its likely effect on the general community, the possibilities IT could provide through increasing the level of services offered to the public and the longer term implications on employment and education. The events were conducted to combat the often ill-informed and emotional portrayal of those issues by the popular press and consisted of a number of public forums in which speakers from the IT profession presented information in a format easily digestible by the general public together with an opening to the general public of the computing facilities of tertiary institutions.

\section{Assisting in the dissemination of IT awareness.}

Professional bodies can also assist in spreading IT awareness among the general community. For the past 25 years, the ACS Victorian Branch has conducted an annual Careers Night attended by up to 500 secondary students, teachers and parents. The event explained to students the variety of IT-related careers which they could pursue and the types of academic or vocational courses which they would need to complete in order to attain their goal. In addition, speakers visit secondary schools and universities to tell local groups of students about the increasing importance of IT in business and industry. The activities have had a significant influence on providing a body of high school leavers who are aware of the employment opportunities in IT and able to make informed choices about the path of education which will lead them to careers of interest to them. Developing countries might do well to adopt such outreach activities.

\section{Examination-based criteria for membership.}

The Australian and British Computer Societies conduct their own examinations as an alternative path to membership for those who have not completed a tertiary or post-secondary IT qualification. But such a policy should be seen as a short-term expedient to be employed in the earlier days of the growth of a viable IT profession and should be phased out in the longer term in favour of a requirement of tertiary qualifications for IT professionals.

\section{Accreditation of academic courses.}

Professional bodies play a significant role through the accreditation or certification of educational curricula. This may be done by the independent development of sample syllabi to be used by the educational institutions and/or by the inspection of syllabi developed by the institutions in the light of current best practice and state-of-the-art technology and methodology. The accreditation process may be carried out on an advisory basis or may be given 'teeth' by requiring prospective members to complete an accredited course of study as a prerequisite for membership. The latter policy has long been followed by accounting, law, medicine and engineering professions but has been a source of contention among computing professionals due to the difficulty which IT has always had in viewing itself as a profession, let alone encouraging that view among the general public. 
In addition to the more direct formulation or accreditation of academic curricula as referred to above, professional bodies can play a secondary role as advisors to other groups developing IT-related curricula. Tertiary and post-secondary institutions typically appoint advisory boards or panels to provide input into the curriculum development process. Government education departments also develop curricula for use in primary and secondary schools, and require advice and expertise from various sections of the community in doing so. Professional bodies can play a significant role by providing members for the advisory bodies.

\section{Codes of professional practice and ethics}

The Achilles heel of the IT profession has been its difficulty in coming to terms with its professionalism. Accounting, law, medicine and engineering professional bodies have no qualms about enforcing the skills and knowledge which must be acquired before membership is granted. They have long standing codes of ethics and professional behaviour which - if breached by members - lead to loss of membership. The community has come to expect that professionals display a level of knowledge and behaviour that provides a climate of self-perpetuation of the professions' status. In contrast, the IT community has grown - as did the more hallowed professions in times past and now conveniently forgotten by their members - by recognizing those with a demonstrable talent for doing the work regardless of their background, education or standards of behaviour. Attempts to influence employers to undertake a policy of selective recruitment of employees who are demonstrably educated in the requisite skill and knowledge for IT has proven to be a dismal failure. The professional IT bodies have a duty to the publicat-large to continue to promote a code of professional practice and ethical behaviour which may result in the acceptance of IT as a profession and not merely as an occupation.

\section{The Computer Industry Training Program (CITP)}

A description of a training program which was successfully conducted by the Australian Government and the ACS over a number of years could serve as an example to countries wishing to accelerate the development of an IT infrastructure.

The CITP was active in two Australian states - New South Wales and Victoria over a period of approximately five years. The program was undertaken with to boost the number of trained IT employees available in the marketplace and reduce the number of unemployed. It was a 'sandwich' program consisting of periods of formal education and on-the-job training and experience.

Applicants could apply for the program in one of three intakes during the year. The program was open to all with an interest in an IT career and was actively encouraged among those who were currently unemployed. Encouragement was given by staff in the Commonwealth Employment Service, who tried to find employment for job seekers. No IT qualifications or prior experience were necessary for entry into the program.

Applicants were given an aptitude test to determine, as far as possible, their suitability for employment as trainee programmers. Those achieving what was deemed to be a suitable level in the test were then interviewed by a panel of industry representatives to determine their attitude to IT employment, motivation and likely employability at the end of the training. Those selected as a result of the 
interview were interviewed by prospective employers, who had agreed to participate in the scheme.

The inducement to employers was that the government agreed to subsidize the salary of the employee for the period of the trainees' academic studies. In order to progress to the education phase of the scheme, the prospective trainee had to find a sponsor employer who had to agree to employ the trainee for a two year period following the completion of the initial education phase - subject to a right of dismissal for incompetence or dishonesty.

The sponsored trainees then attended an eight-week full-time program organized to produce trainee programmers and conducted by a postsecondary education institution. At the end of the eight-week training, the trainees went to work for their sponsoring employers for two years. In the second year, the employers were obliged to release the trainee for a further 2-week training course designed to equip them with more job skills.

The scheme was jointly administered by the Commonwealth Department of Employment and the ACS, and worked well over a number of years. It provided an opportunity for hundreds of trainees to enter the IT employment arena who would not otherwise have had the chance and encouraged employers to expand their employee base at minimal cost and risk.

One of the advantages of being a follower rather than a leader is the ability to avoid the pitfalls into which others have fallen. Countries wishing to build their IT resource capacity should give serious consideration to their policy of IT education and training at all levels. The IT professional bodies are well placed to assist in the process by proactive policies of accreditation and advice to educational institutions as well as playing a role in the education of the public at large. By pursuing a wide range of activities, the professional bodies have created a body of well-informed and well-educated IT practitioners to swell their own ranks. They will also have the opportunity to influence the level of professional behaviour and competence exhibited within their community.

\section{$5 \quad$ BIOGRAPHY}

Peter Juliff is Professor of Management Information Systems at Deakin University, Melbourne, Australia. He has spent the last 34 years working in the IT profession, over 20 of which have been as an academic. He is the Chief Examiner for the Australian Computer Society and the Chair of IFIP Working Group 3.4 on Vocational and Professional IT Education. He is the author of several books on computer science and software design, and has conducted professional development courses throughout Australia, Malaysia, Singapore and China. 